Review

\title{
Systemwide Considerations for Electrification of Transportation in Islands and Remote Locations
}

\author{
Efrain $\mathrm{O}^{\prime}$ Neill-Carrillo $\mathbb{D}^{\mathrm{D}}$, Matthew Lave * and Thad Haines
}

check for updates

Citation: O’Neill-Carrillo, E.; Lave,

M.; Haines, T. Systemwide

Considerations for Electrification of Transportation in Islands and Remote Locations. Vehicles 2021, 3, 498-511. https://doi.org/10.3390/vehicles 3030030

Academic Editor: Yongzhi Zhang

Received: 2 July 2021

Accepted: 29 July 2021

Published: 6 August 2021

Publisher's Note: MDPI stays neutral with regard to jurisdictional claims in published maps and institutional affiliations.

Copyright: (c) 2021 by the authors. Licensee MDPI, Basel, Switzerland. This article is an open access article distributed under the terms and conditions of the Creative Commons Attribution (CC BY) license (https:// creativecommons.org/licenses/by/ $4.0 /)$.
Sandia National Laboratories, Albuquerque, NM 87185, USA; oneill@ieee.org (E.O.-C.); jthaine@sandia.gov (T.H.)

* Correspondence: mlave@sandia.gov

\begin{abstract}
Electric vehicles (EVs) represent an important socio-economic development opportunity for islands and remote locations because they can lead to reduced fuel imports, electricity storage, grid services, and environmental and health benefits. This paper presents an overview of opportunities, challenges, and examples of EVs in islands and remote power systems, and is meant to provide background to researchers, utilities, energy offices, and other stakeholders interested in the impacts of electrification of transportation. The impact of uncontrolled EV charging on the electric grid operation is discussed, as well as several mitigation strategies. Of particular importance in many islands and remote systems is taking advantage of local resources by combining renewable energy and EV charging. Policy and economic issues are presented, with emphasis on the need for an overarching energy policy to guide the strategies for EVs growth. The key conclusion of this paper is that an orderly transition to EVs, one that maximizes benefits while addressing the challenges, requires careful analysis and comprehensive planning.
\end{abstract}

Keywords: electric vehicles; charging stations; vehicle-to-grid

\section{Introduction}

Electrification of transportation, especially through the adoption of personal electric vehicles (EVs), is increasing around the world. Though this electrification comes with many benefits and opportunities, it also presents some challenges to grid operators, energy planners, and decision makers. This paper describes the opportunities and challenges associated with integrating electric vehicles into island and remote locations.

EV motors are more energy efficient than internal combustion engines (ICE). Even when accounting for typical losses in electric generation and transmission, EVs require less energy per mile traveled. Table 1 shows an example using the Hyundai Kona which was chosen because it has both gasoline and electric models, allowing for direct comparison. However, this result would hold true for other vehicles due to the relative efficiencies of electric motors versus gasoline engines. The energy efficiency of EVs can be increased further by co-locating generation with the EV charging stations to reduce or eliminate transmission losses. Because of the higher energy efficiency, EV adoption results in benefits such as reduced fuel costs, limited emissions, and decreased maintenance needs compared to conventional gasoline vehicles. 
Table 1. Gasoline vehicle and EV miles traveled per unit of energy.

\begin{tabular}{cccc}
\hline Vehicle Type & Energy Delivered to Vehicle & Motor Efficiency & Combined Efficiency \\
\hline Gasoline & $\begin{array}{c}33.7 \mathrm{kWh} \text { per gallon [1] does not account } \\
\text { for energy used in delivery to pump }\end{array}$ & 30 miles per gallon [2] & $0.9 \mathrm{miles}$ per kWh \\
2019 Hyundai Kona & $\begin{array}{c}\text { 33\% of energy input to powerplant [3] } \\
\text { Electric }\end{array}$ & $28 \mathrm{kWh}$ per 100 miles [2] & $1.2 \mathrm{miles} \mathrm{per} \mathrm{kWh}$ \\
2019 Hyundai Kona EV & due to generation and transmission losses & & \\
\hline
\end{tabular}

In remote and island areas, the benefits of EVs can be even more significant than on mainland systems. For example, fuel supply chains for island and remote communities are particularly volatile in both price and availability, so the higher efficiency and fuel flexibility of EVs (EVs can charge using electricity generated from any fuel) present an opportunity to stabilize and reduce transportation costs. EVs represent an important socio-economic development opportunity for remote and island locations because they hold the promise of reduced fuel imports, are an electricity storage resource, can provide grid services, and can result in improved environmental and health conditions. To directly show the cost savings achievable through electrification of transportation, Figure 1 shows the comparison of the cost of a gallon of gasoline to an equivalent value for EVs. In nearly all cases, EVs have a reduced cost of operation when compared to gasoline vehicles. A modified eGallon was used [4] for this comparison, based on miles per gallon and $\mathrm{kWh} / 100$ miles for 2019 Hyundai Kona gasoline and electric vehicles.

Beyond direct cost savings, the potential abilities to (a) control EV charging as a form of demand response to support the centralized electric grid, and (b) couple EV charging with distributed energy resources (DERs) such as rooftop solar photovoltaics (PV) are particularly valuable features of the electrification of transportation in island and remote systems. Coupling with PV can not only lessen grid impacts (dampen positive or negative ramps in net load), but can also be used in emergency-response applications to charge EVs directly from the PV when the centralized electric grid is out [5].

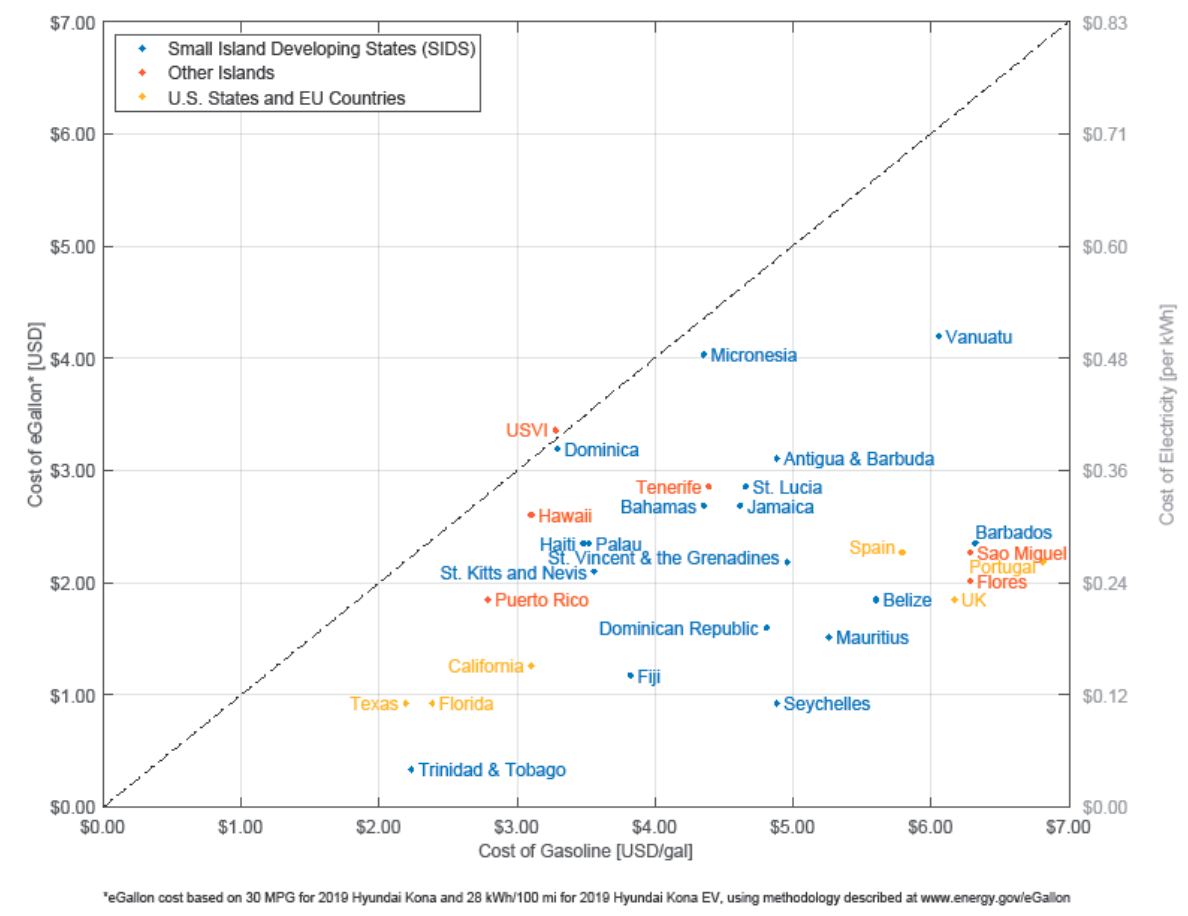

Figure 1. Cost of a gallon of gasoline versus an EV "eGallon" (most data from [6,7]).

Yet, in the smaller electric grids of remote and island areas, relatively modest amounts of EVs can result in significant increases in total electric load, which could pose challenges to grid operations. Technical obstacles include grid reliability issues, increased generation 
capacity needs due to shifts in daily peak demand, and grid upgrade and maintenance costs [8]. High EV penetration (percentage of total load due to EVs) in remote and island systems may require large grid and charging infrastructure investments and supportive policies, which might not currently exist in small islands with uncertain regulatory/policy environments [9].

This paper documents previous research and implementation efforts for EVs in remote and island areas. The works described focus on island or remote energy systems and their grid impacts as well as mitigation approaches for high EV penetrations. Key topics include: (1) the impact and potential mitigation options of integrating EVs into remote and island electric grids and, (2) the need for an overarching energy policy that can serve as a framework or guide to EV adoption strategies. The importance of a holistic energy policy is illustrated through case studies on the impact differing policies have had on EV adoption and operation.

\section{Grid Impact Concerns of Uncontrolled EV Charging}

The cumulative charging of EVs can have an impact on grid performance and stability, especially on smaller isolated grids [7]. Uncontrolled charging can compromise the grid's reliability, security, efficiency, and economy by increasing total grid load during inopportune time periods [10]. Even in the early stages of EV adoption, isolated overloading of certain grid components may occur. Level 1 (up to $2.4 \mathrm{~kW}$ ) or Level 2 (up to $7.6 \mathrm{~kW}$ ) EV chargers [11] may increase the instantaneous load in a home by double or more, which could lead to overloading of a distribution service transformer or lowvoltage line segment. As EV penetrations increase, simultaneous charging can overload substation transformers, as well as high-voltage line segments. Overloads are a concern because they can result in thermal damage including reduced equipment lifetime or even catastrophic failure.

Two interrelated studies modeled the impact of EV charging in the island grid of São Miguel, Azores, Portugal for a group of residential customers [12] and for an industrial customer allowing employee workplace charging [13]. São Miguel has a total system load of $140 \mathrm{MW}$ [14], though the residential load considered in [13] was 292 dwellings totaling $140 \mathrm{~kW}$ at peak load, and the industrial load in [12] also peaked around $140 \mathrm{~kW}$. Despite the similar peak load values, the transformer serving the residential customers (630 kVA) was much larger than the one serving the industrial customer $(250 \mathrm{kVA})$, as the residential transformer was sized based on expected seasonal increases in the residential load. Due to all EVs beginning to charge at the same time and the transformer size differences, overloading was found through simulations at $75 \% \mathrm{EV}$ penetration in the residential scenario but at only $40 \% \mathrm{EV}$ penetration for the workplace charging scenario. Both studies additionally estimated a shorter transformer lifecycle when EV penetrations led to transformer overloading. In the residential case, $3 \mathrm{~h}$ of daily transformer overloading due to $100 \% \mathrm{EV}$ penetration would result in approximately $6 \mathrm{~h}$ of transformer life reduction each day. The industrial transformer was particularly stressed by fast-charging scenarios (regular charging rates were up to $7.4 \mathrm{~kW}$, fast-charging rates were up to $50 \mathrm{~kW}$ ), with approximately $58.5 \mathrm{~h}$ of service life lost for every one day of fast-charging operation at $35 \%$ penetration. This was heavily influenced by the transformer size and 3 daily overload peaks caused by all EVs starting to charge at the beginning of each work shift.

An example of line overloading comes from a study modeling an actual distribution feeder in the island of Trinidad [15]. While Trinidad has an installed capacity of about $2200 \mathrm{MW}$ [16], the feeder studied had about $5 \mathrm{MW}$ of load. An increased amount of line overloading was observed when EV penetration levels reached $10 \%$, though it should be noted that some line overloading is found to occur even before EVs are added. Consistent with the note in the previous paragraph, the authors comment that," ... known issues such as pole-mounted transformer overloading were intentionally neglected due to the understanding that it is inevitable that overloading will occur and can be addressed by simply resizing to a higher transformer capacity" [15]. 
As EV penetrations become significant, increased loads due to EV charging may cause voltages on distribution grids to drop below acceptable voltage limits. A common range of acceptable voltages is $+/-5 \%$ (e.g., ANSI C84.1 Range A [17]), such that at a 120 V customer, for example, the centralized grid must deliver voltage between $114 \mathrm{~V}$ and $126 \mathrm{~V}$. Having too low or too high of a voltage on a distribution feeder can result in adverse impacts including unscheduled maintenance, early equipment replacement, damage to customer equipment, and in extreme cases, increased grid outages resulting in lost revenue [1]. Several studies of island systems have simulated that voltages will decrease below allowable limits during the simultaneous charging of many EVs.

The study using the feeder model from Trinidad described earlier found that voltages dropped below acceptable limits at several feeder nodes when EV penetrations of as little as $5 \%$ were implemented [15]. Voltages were already very close to lower limits before any EVs were connected, a state which may be common in island and remote systems due to grid design and operation considerations.

A related case study comes from the island of Jeju, South Korea. Jeju has approximately $630 \mathrm{MW}$ of installed power generation capacity [18] on the island but a peak demand of $930 \mathrm{MW}$. Additional power is received from underwater transmission lines from the mainland, though it is expected in the future (around 2030) that Jeju may export excess wind power generation to the mainland [19]. This complicated bidirectional, time-dependent flow of power makes it particularly important that EV charging not negatively impact electric grid operations. A study using a simple feeder topology and typical load profiles (feeder load of approximately 6.5 MW) found that 20\% EV penetrations led to voltage drops below acceptable limits [20]. Increased power losses and new timing and magnitudes of peaks in electric load demand were also observed when EVs were integrated.

\section{Mitigation of EV Impacts}

The challenges of EV integration motivate research on the impact, mitigation, and effective controls of EV charging. This research will immediately benefit remote and island systems and will also be valuable to larger mainland systems in coming years as EV penetrations become significant on larger mainland electric grids, which will take longer.

It is very important to reduce the negative impacts to the electric grid from the early stages of EV adoption to avoid limits on further EV adoption [7]. While upgrades to electric grid infrastructure, such as increasing the size of conductors (to avoid line overloading), increasing the size of transformers (to avoid transformer overloading), or adding voltage control devices (to keep voltage in allowable ranges), can directly mitigate most concerns, they typically are high-cost and require significant installation efforts. Cheaper and easier to implement mitigation strategies will involve the EVs in grid operations, including simple control strategies for EV charging (e.g., use of timers), controlled EV charging in response to the state of the electric grid, EV chargers providing grid services to assist with grid operations, and integration of EVs with DERs.

Controlled charging is the most basic grid-to-vehicle service and is often the simplest to execute within existing infrastructure [21]. Controlled charging is either passive (e.g., via a timer) or active (e.g., responding to the grid voltage level). The most common control strategy is "time of use" pricing that incentivizes customers with reduced rates during specific times, typically corresponding to times of low system load. "Demand response" is a more active control scheme where the utility dispatches a signal to customers to control their EV charging, which typically occurs during a period of high system load.

More advanced smart charging was shown effective in a study for the island of Guadeloupe (peak island demand of $254 \mathrm{MW}$ [22]). The effects of EV deployment were modeled in consideration of local electricity generation, demand, and driving patterns (the estimated average daily driving distance is $41 \mathrm{~km} \approx 25 \mathrm{mi}$ ). The simulations highlighted the importance of parameters such as the maximum charging power allowed and the number of charging stations deployed to increase the flexibility of EVs [23]. Results showed that high penetration of EVs could be achieved using fleet-operator-based charg- 
ing. Controlled charging was important to help increase the use of renewable energy while keeping the "apparent penetration" of renewable energy below $30 \%$ as required in Guadeloupe [23].

EVs can provide grid support services (also known as "ancillary services") to reduce their impact and support electric grid operations. For example, EVs can be used as a form of demand response, reducing their charging during periods when the electric grid is stressed, such as if a generator fails or when load is unexpectedly high. EV chargers can also be configured to provide voltage support, such as through volt-var control schemes which have become common in PV inverters [7].

A study in São Miguel looked at how EVs could support an increase in the use of renewable energy and presented possible grid-related revenues for EV owners [24]. The study assumed bi-directional EV charging, that is, EVs could be used as dispatchable storage devices. When EV owners were compensated financially for providing ancillary services, EVs had lower total costs of ownership than conventional vehicles, even though EV purchase costs were significantly higher than conventional vehicles. However, as EV penetration increased, revenues from providing grid services decreased for individual EV owners. An important finding was if high EV penetrations are achieved and controlled effectively, nearly all of the variability in the total system's electric demand curve can be eliminated, which would simplify and reduce the cost of electric generation needed.

\section{Strategically Locating EV Chargers}

\subsection{EVs at Robust Grid Nodes}

Another way to mitigate the impact of EV charging is to place chargers at robust nodes in the electric grid such that large numbers of chargers can be installed without overloading system components or causing voltage issues.

EV chargers are already prolific on the island of Jeju, South Korea, with 1103 express charging points and 344 slow charging points (full recharge overnight) [25]. The voltage and loading challenges highlighted in [20] are being addressed through strategic placement of new chargers [26], among other strategies (e.g., encouraging EV charging stations powered from renewable stations [27]).

The island of Sardinia (total installed power capacity of approximately 5000 MW [28]) was used to test a combined planning and design approach for public EV charging infrastructure [29]. A coarse distribution of charging stations over the selected zones of interest was done initially considering the charging demand area. Subsequently, the charging infrastructure locations were refined to comply with system constraints. As a result, charging station locations were identified that accommodated grid constraints yet were still convenient to EV users ( $>85 \%$ of municipal areas were within $500 \mathrm{~m}$ of a charger) [29].

In Iceland (total installed power capacity of approximately $2770 \mathrm{MW}$ [30]), strategic locations of EV chargers make it possible to circumnavigate the country by EV via the Ring Road, and $13.5 \%$ of new vehicles registrations were EVs in 2018. The size of the island ( $500 \mathrm{~km}$ by $350 \mathrm{~km} \approx 311 \mathrm{mi}$ by $217 \mathrm{mi}$ ) means that EVs can complete most trips on a single charge. Iceland's electricity is almost $100 \%$ from renewable energy, making this a low-carbon transition for the transportation sector [31]. Up to 90 additional charging stations are expected to be deployed by 2022 in Reykjavík alone [32].

In addition to strategically locating new EV charger installations, it can also be valuable to strategically utilize EV chargers based on location, especially when considering the current state of the electric grid. In Waiheke Island, Auckland, New Zealand (population of 7689; connected to main New Zealand grid via underwater cable), EV chargers will coordinate with the utility's Distributed Energy Resource Management System (DERMS) to optimize the use of EVs and distributed energy sources. Currently, most EVs are charged at home [33], but planning is in place, in consultation with the community, for a combination of new smart chargers in homes and in public locations [34]. Strategically locating these home and public chargers will allow the utility to better manage demand (through smart charging), improve grid resilience, and avoid investments in infrastructure. 


\subsection{EVs with Other Distributed Energy Resources}

There can be significant benefits to coordinating EVs with other DERs including solar $\mathrm{PV}$, wind power, and storage. Effective coordination in remote and island locations can result in reduced grid impact from both EVs and DERs, reduced fuel costs, lower emissions, more efficient local consumption, and energy resilience benefits.

Once EV batteries reach the end of their useful life, they can be removed from the vehicle and repurposed as grid-connected static storage [7]. It should be noted, though, that in remote and island systems where distances traveled are typically shorter than mainland areas, there may be more tolerance for battery capacity degradation in the vehicle.

To take advantage of these benefits, French coast island Belle-Île-en-Mer (population 5000 , but tourist activity in summer months results in approximately 30,000 people [35]) will combine EVs and renewable energy to become a "smart island". Island residents and visitors will have access to a fleet of EVs through a car-sharing service [36]. Charging stations will get power from solar panels installed on the rooftops of large buildings. Power from the solar panels will be routed between buildings and cars as needed. Renault will also supply used EV batteries to store energy from solar panels [36]. These are batteries from electric cars that have degraded too much for EVs but are good enough for stationary storage.

Hybrid power systems (a combination of different energy sources such as solar, wind, and diesel generators) were studied [37] to determine the best configuration of batteries for use in charging stations in rural areas such as Labuan Bajo, Indonesia (population 5774 [38]). Different types of generation (wind, solar, and other small DER) and three types of storage (lead acid, lithium ion, and lithium ferro phosphate) were considered. The optimum solution for Labuan Bajo was solar plus a small DER system using a lithium ferro phosphate battery, though similar analysis could be carried out in other island areas and may result in different optimal configurations, especially as energy storage technologies evolve.

An optimal power generation planning study was completed for a microgrid in Santa Cruz and Baltra, Galapagos Islands (peak demand 7.26 MW [39]), to assess the impact of new EV and induction stoves (IS) [40]. This planning model used nine simulation scenarios to determine the impact of different penetration levels of EVs and ISs. A sensitivity analysis based on three different projected diesel prices was performed to take diesel price uncertainty into consideration. The results showed that new PV generation would improve overall system costs, especially if diesel prices are high.

EVs can be strategically controlled to enable higher penetrations of variable renewable energy resources by increasing charging during times of high renewable generation and decreasing charging during periods of low renewable energy generation. An example is shown for the Portuguese island of São Miguel where charging strategies were examined [41]. The EVs were able to help flatten the island's daily demand curve for different scenarios up to $32 \%$ EV penetration. Similarly, a study for the Portuguese island of Flores (peak load of approximately $2 \mathrm{MW}$ [42]) looked at how EVs could increase the use of renewable energy [42]. Optimal charging strategies were studied using a dynamic programming algorithm, and the main result was that controlled charging of EVs reduced both the need for backup generation and the amount of wind energy curtailed.

Overall, the works presented in this section demonstrate that EVs charging from renewable DERs can be mutually beneficial. EVs benefit from cheaper electricity with lower emissions, while renewable DERs can increase utilization and even allow for new installations as EVs utilize power which may have previously been curtailed due to a lack of demand or a concern over high penetrations of renewable energy resources.

\section{Coordinated Policy and Economic Decisions}

There are policy and economic considerations, beyond the technical feasibility, that are essential for successful EV deployment in remote and island locations. Many remote and island locations have good potential for EVs because they typically have short driving distances and often have available renewable resources that can be leveraged to generate 
power locally, often at lower cost than centralized grid power. However, it is important to develop holistic energy policies and consider the local context when addressing policy and economic challenges and to adapt implementation strategies accordingly.

\subsection{Considerations in the Caribbean}

In the Caribbean, for example, the long-term impacts of an EV transition need careful consideration due to limits on electrical and business infrastructures [43]. A comprehensive energy plan that is coordinated with broader socio-economic policies is needed to inform economic decisions and resulting infrastructure investments that support a potential EV future [8]. If the $\mathrm{EV}$ obstacles are carefully pondered and the technology is proven to benefit the local economy, the relatively flexible governance structures in many small islands could support rapid adoption of EVs [43].

On some islands, the high initial cost of EVs makes them economically infeasible for individual consumers when compared to conventional vehicles [8]. High taxes and fees on EVs and the lack of a long-term vision are key obstacles on some islands [44]. For example, a Nissan Leaf costs USD 52,500 in Barbados, compared to USD 31,600 in the mainland U.S. The price differential is mainly due to the local road tax, vehicle import duties, and value-added tax [45]. Caribbean countries face the challenge of tight budgets that are dependent on the revenue from import taxes, thus limiting their ability to use these incentives as leverage as is done in other countries [9]. A used EV market, with vehicles that are no longer suitable for mainland distances, is an alternative used on some islands [33].

Trinidad and Tobago is an example of an island state that focused on the development of an EV policy to support long-term EV penetration. Researchers from the University of the West Indies and the Government Electrical Inspectorate drafted a plan that included analysis of the EV registration processes, roles of local stakeholders, identification of needed legislation, and coordinated enforcement processes. Additionally, internationally accepted practices were analyzed and adapted [8], resulting in Trinidad and Tobago eliminating import taxes for most EVs. A total tax exemption might not be practical on other islands, but a tax reduction (even if temporary to spark the market) for EVs could be a possible solution. For example, Barbados lowered its import duties for EVs as compared to similar size ICE vehicles ( $10 \%$ vs. $45 \%$ import duty, and $20 \%$ vs. $46.95 \%$ for excise tax) [45].

The Caribbean Community (CARICOM) Regional Electric Vehicle Strategy (REVS) Framework provides the foundation for a transition to EVs in the Caribbean [46]. The REVS acknowledge the importance of changing transportation systems at the local level, as well as accounting for driving behaviors and transportation preferences of individuals. The framework provides guidelines in the following areas: Policy and regulation; technology and infrastructure; capacity development and awareness; finance, market development and innovation. It has a strong emphasis in a market approach, inclusion of relevant stakeholders, capacity building, prioritization of public and commercial transportation, and the key role of technology and infrastructure improvements. Other important regional references for the Caribbean are the position paper "The Future of E-Mobility in the Caribbean" from the Caribbean Centre for Renewable Energy \& Energy Efficiency (CCREEE) [47] and the report "Electrified Islands: The Road to E-Mobility in the Caribbean" [45].

\subsection{Successful EV Experience: Barbados}

In Barbados, a private company spearheaded a successful EV business model with support of the local government, a non-governmental organization, key business partners, and a supportive regulatory framework [48]. Barbados is an example of how barriers to wide implementation of EVs and associated infrastructure can be easier to overcome on islands. Barbados is among the top ten users of EVs per capita in the world with 1.36 vehicles per 1000 persons (based on 390 EVs by the end of 2018) [43,49]. Drivers do not have range anxiety because average local distances traveled in a typical day are short in a 21-mile-long island, and drivers are never more than a few kilometers from a charging 
point [9]. Charging is inexpensive compared to gas or diesel [48]. Each full charge costs approximately USD 7.50 for 78 miles $(\approx 125 \mathrm{~km})$ of driving, which is about $1 / 3$ of the cost of running an ICE over the same distance.

There are more than $350 \mathrm{EVs}$ and over 50 charging stations in Barbados. The forecast predicts that $10 \%$ of the island's population (about 28,000) will drive EVs in five years [48]. The success in Barbados is driven by a local company, Megapower, which sells EVs, charging infrastructure, and solar energy products to Barbados and other Caribbean nations, and works with diverse partners from governments and electric utilities as well as the private sector [48].

The support of local government and several key business partners have been essential. Barbados also has a supportive regulatory framework, a feed-in tariff for solar PV, and a very active local NGO, the Barbados Renewable Energy Association (BREA), that helps to shape the local renewable energy policies [48].

\section{The Need for Comprehensive Energy Policies}

Phu Quoc, Kien Giang, Vietnam is the largest island in Vietnam, with a population of 107,000 and about 222 square miles, or 570 square $\mathrm{km}$ (its longest road is 31 miles, or $50 \mathrm{~km}$, long) [46]. Different EV adoption scenarios were evaluated up to the year 2030, varying EV penetration in taxis and buses up to $20 \%$, and electric motorcycles from 40 to $50 \%$ penetration. The results were used to develop the following policy proposals for EVs: no import and consumption taxes, no registration and road fees, reduced rates for EV charging, subsidy to buy home EV chargers, and incentives for EV buyers such as personal income tax deduction and no parking fees. The authors also proposed increasing the following charges for traditional transportation: import and consumption taxes, registration and road fees [50]. These results also indicate that developing green energy requires more comprehensive government policies.

Researchers studied the electrification of the heat and transportation sectors in the Aran Islands (Ireland) utilizing renewable energy to determine the fuel and emission savings. A smart control algorithm was designed to optimize the timing of EV charging and heat pump (HP) use. Results indicate a dramatic reduction in total energy consumption through the electrification in the heat and transport sectors. It is recommended that HPs be prioritized over EV deployment due to the nature of energy demand on the island and the capital costs involved [51]. Thus, in this case the recommendation prioritizes energy opportunities (such as heat pumps) that might be easier or less expensive than EVs.

Flexible transit solutions have evolved in Germany to include EVs through state-run initiatives seeking to promote sustainable mobility. Using EVs in rural areas also opens new markets in more demanding contexts: in general, rural areas are more dispersed than urban areas, forcing residents to travel longer distances to fulfill daily needs [52]. The City of Kerpen is composed of eleven villages near Cologne, Germany. Recently, most of the energy infrastructure came under the control of the city. It plans a fast transition towards flexible and decentralized generation, storage, and smart traffic management through master plans which cover development areas of residential buildings as well as commercial zones [53]. A key approach proposed is to use single buildings as the basic module of the energy management strategy. By operating the buildings in this way, each building contributes to the overall stability of the local distribution grid which in turn implicates optimized pricing. For example, the load profile forecast for charging EVs in the building's underground parking is calculated and used in the overall building automation control and energy management systems [53].

Reunion Island, an overseas jurisdiction of France, provides a good example for energy policy fostering renewable technologies to supply electricity and highlighting the crucial role of incentives [54]. The 100\% renewable power generation goal by 2030 serves as the foundation for the sustainable energy transition of Reunion Island and was supported by a bottom-up cost-optimization model. A key strategy towards achieving that goal is to have EVs totaling 1400 GWh by 2030 in a location where most daily trips are less than 
$100 \mathrm{~km}(\approx 62 \mathrm{mi})$. The plan includes important EV contributions to the grid such as peak shaving, grid frequency control, and generation-load balance.

\section{Perceptions and Local Needs}

Consumer perceptions such as uncertainties of new technologies and the local context are key considerations $[9,43]$. For example, an EV study on Western Samoa concluded that to make EVs accessible to society, the concept of electro-mobility needs to be reframed in the context of local affordability and cultural considerations [55]. This could include EV retrofit conversions of second-hand cars and reducing the importance of personal ownership vehicles, such as through a car sharing service. Climate considerations are listed as one of the motivations for the research work.

Another example of the importance of the EV context, within continental Africa, is the Sub-Saharan region. More than $70 \%$ of people live in rural areas, and they mainly move by buses or motorcycles. The primary positive impacts of better mobility (both individual or collective) are related to the rural economy: increased productivity, increased income, access to health care, and easier access to schools and education [56]. Electric mobility in off-grid areas is an opportunity for increasing the electrical energy access in rural areas through a coupled approach: small (distributed) power grid plus electric transportation. Electric motorcycles are much cheaper than a car and could be the initial best option for rural regions. E-motorcycle batteries are small and can be recharged from a small PV panel. Typically, the battery size is around $2 \mathrm{kWh}$ for a $60 \mathrm{~km}(\approx 37 \mathrm{mi})$ range and it could be fully charged with a single PV panel (surface of $1.5 \mathrm{~m}^{2}$ ) for one day [56].

In Sub-Saharan Africa, researchers and students from Nigeria, Ghana, and Germany have been working since 2013 to design a new vehicle concept (the aCar project) that fulfills regional requirements [57]. Nigeria, Ghana, and Kenya were included in the case study since they have similar mobility gaps in rural areas and a suitable vehicle that meets all local requirements does not currently exist [57]. The result of the research and design process was a vehicle concept that meets the needs of the people living in rural areas of Sub-Saharan Africa by addressing the local challenges: poor road conditions, road safety, and the affordability of the vehicles. This new concept exemplifies the importance of considering the local context when evaluating EV options, including possible nontraditional options that might be better aligned with cultural and local preferences. For example, electric scooters and a possible battery swapping model [58] and alternatives that address local economy needs (e.g., tourism preferences) [59].

\section{Cost Issues and Utility Business Changes}

EVs represent a new business opportunity for utilities in remote and island areas around the world through increased electric demand. To facilitate this, some utilities, such as those in the Bahamas, Turks and Caicos, and St. Lucia are installing EV chargers to encourage EV adoption [9]. However, there may be significant additional electric grid infrastructure investments required to accommodate this new load. Financing these infrastructure upgrades can be challenging, and utility rate structures may need to be revised. The mitigation strategies listed in Sections 3 and 4 can help defer or eliminate infrastructure upgrades.

Production cost impacts for different levels of EV penetration were considered for Barbados. Barbados has $240 \mathrm{MW}$ installed capacity, a peak demand about $170 \mathrm{MW}$ and 287,000 inhabitants. A daily average driving distance of $40 \mathrm{~km}(\approx 25 \mathrm{mi})$ was assumed. The results showed that production costs increase the most with uncontrolled charging at night. Once controlled charging strategies are used, costs begin to decrease. The least cost is achieved when controlled charging occurs during the day and there is close coordination with the grid (i.e., vehicle-to-grid services) [60]. When EVs can provide ancillary services, production costs from charging EVs can be limited, more renewable energy can be integrated, curtailment is reduced, and the investments needed for grid-connected storage are reduced [60]. 
In Finland, the EV target is 250,000 passenger cars by 2030. At the same time, a significant number of HPs will be installed in detached houses replacing old heating systems such as oil-fired boilers. The effects of EVs and HPs on electricity consumption in Finnish rural areas were modeled and analyzed resulting in average load changes at mediumvoltage lines $(10-30 \mathrm{kV})$ or primary substations $(110 / 20 \mathrm{kV})$, with the more significant increases occurring downstream at the secondary transformer. EVs or HPs may cause the transformer capacity to be exceeded. These load changes challenge the distribution business model because of the way rates are structured (i.e., a function of delivered energy). Power-based rates could be used so that all or part of the revenue would be collected using a power component [61]. Energy-based or volumetric rates are the usual way for electric utilities to charge customers based on their energy consumption in kWh. Power-based rates, which include capacity rates, have been proposed to account for the increase in customer-owned generation which contradicts the assumptions made when basing rates on energy consumption.

The 49 inhabited Croatian islands may be able to meet their energy needs from locally available renewable energy sources [62]. Researchers from the University of Zagreb completed studies for the islands of Krk, Unije, and Losinj in the North Adriatic Sea, and Mljet, Lastovo, and Korcula in the South Adriatic Sea. Building smart energy systems on these islands has become a key strategy to increase penetration of renewable sources and make local transport more sustainable. The island of Vis (pop. 3600) was used as a case study to integrate renewable energy sources, demand response, and EVs in a harmonized planning effort. The main recommendation was to use alternative financial mechanisms, such as energy cooperatives and energy service company business models including PV in the Croatian islands' energy transition [62].

\section{Summary}

An orderly transition to EVs, one that maximizes benefits while addressing the challenges, requires careful analysis and comprehensive planning. The cases presented in this paper can be used to advance starting points for EV planning in remote and island locations, though additional research questions remain.

\subsection{Lessons Learned}

The key challenges for the electrification of transportation and potential solutions in remote and island locations are summarized below:

Technical challenges associated with high levels of EV penetration include added stress on electric infrastructure.

- Uncontrolled EV charging could affect reliability, security, efficiency, and economy at a faster rate in small, isolated grids, even in early EV stages [7].

- Increased peak loading and costs to the utility in upgrading and maintaining infrastructure [8].

Mitigation strategies for addressing these challenges include:

- Rate-based incentives such as demand charges, time-of-use rates and dynamic pricing $[7,21]$.

- Smart charging technologies to reduce grid costs, provide grid services, and increase renewable energy utilization $[8,23,36,42,51,60]$.

Examples of policy, regulatory, and user-related challenges in remote and island locations include:

- Lack of long-term policy vision [44] which impedes understanding the far-reaching impacts of EV transitions [43].

- High import duties, high initial costs, and limited availability of EVs [43,44,48], the difficulty of offering incentives due to limited government budgets [9], and uncertain regulatory/policy environment [48].

- Consumer expectations must be managed $[43,48]$ including aversion to new technology and lack of familiarity [48,58]. 
To address these challenges, there is a broad spectrum of policy and economic strategies to support EV deployment including:

- Coordinate policy and economic goals through a comprehensive energy policy framework or strategy $[43,50,51]$.

- Highlight the crucial role of incentives policies on EVs [54,58] and adapt best practices [8].

- A supportive government and buy-in from and partnerships with stakeholders across different sectors and communities $[8,9,34,40,48,58]$.

- Leverage transportation modes that are familiar locally and meet local needs $[57,59]$ (e.g., motor bikes instead of cars).

- Cost and business strategies: Diversify utility business, for example through EV services market and filling EV market voids [9,58]; explore alternative financial mechanisms such as energy cooperatives and ESCOs [62]; focus on solutions for short driving distances and use of local energy resources [54], and identify business arrangements for reusing EV batteries (as an incentive for new owners while stimulating local economies) $[7,36,48]$.

\subsection{Pending Research Questions}

While this review of previous efforts has illustrated the challenges and opportunities for EVs in remote and island territories, several important research questions remain, including:

- How will EV adoption be impacted by the per-mile costs of electric versus gasoline vehicles (Table 1)? Will stronger incentives or other schemes be needed in locations with relatively low gasoline prices compared to electricity prices?

- How can EV charging be best controlled to mitigate grid impacts? How do optimal controls differ between personally owned vehicles and fleets of commercial or industrial vehicles?

- Can EV and photovoltaic or other distributed energy resources be paired and operated in a way to both lower costs and increase energy resilience?

- Will policies that are successful in certain areas also translate to success in other territories or countries?

- How can utility business models best adapt to enable high EV adoption but also strong utility financial health?

As research continues and as $\mathrm{EV}$ penetrations increase resulting in more experience with EVs in island and remote territories, these questions will begin to be addressed. Lessons learned from island and remote territories are likely to be valuable as for mainland areas, where high EV penetrations will be achieved more slowly due to their larger electric grids.

Author Contributions: Conceptualization, E.O.-C. and M.L.; methodology, E.O.-C.; writing-original draft preparation, E.O.-C.; writing—review and editing, M.L. and T.H.; visualization, M.L.; project administration and funding acquisition, M.L. All authors have read and agreed to the published version of the manuscript.

Funding: This research was funded by the U.S. Department of Energy's Energy Transition Initiative (ETI). Sandia National Laboratories is a multimission laboratory managed and operated by National Technology \& Engineering Solutions of Sandia, LLC, a wholly owned subsidiary of Honeywell International Inc., for the U.S. Department of Energy's National Nuclear Security Administration under contract DE-NA0003525. This paper describes objective technical results and analysis. Any subjective views or opinions that might be expressed in the paper do not necessarily represent the views of the U.S. Department of Energy or the United States Government.

Acknowledgments: The authors gratefully acknowledge the valuable discussions with and recommendations from Peter Cappers at Lawrence Berkeley Laboratory and Kyle Fleming and Megan Grant at the U.S. Virgin Islands Energy Office.

Conflicts of Interest: The authors declare no conflict of interest. 


\section{References}

1. N.M. Corporation. Powering Resilience: How EVs Can Help Communities Bounce Back after a Disaster. Available online: https:/ /global.nissannews.com/en/releases/release-b8a1567ee6066d582c91ef8f1d0b47ad-190920-00-e (accessed on 10 July 2021).

2. Numbeo. Gasoline, Petrol Prices. Available online: https://www.numbeo.com/gas-prices/ (accessed on 6 August 2020).

3. Meetoo, C.; Bahadoorsingh, S.; Jaglal, D.; Balbadar, V.; Sharma, C.; Baboolal, K.; Williams, M. Electric vehicle policy formulation framework for SIDS in the Caribbean. In Proceedings of the 2018 IEEE Transportation Electrification Conference and Expo (ITEC), Long Beach, CA, USA, 13-15 June 2018.

4. Hares, S. Caribbean Islands Plug into Electric Car Revolution. 2018. Available online: https://www.reuters.com/article/ us-islands-caribbean-transportation-elec/caribbean-islands-plug-into-electric-car-revolution-idUSKBN1KF1O5 (accessed on 1 October 2019).

5. Gay, D.; Rogers, T.; Shirley, R. Small island developing states and their suitability for electric vehicles and vehicle-to-grid services. Util. Policy 2018, 55, 69-78. [CrossRef]

6. Innovation Outlook: Smart Charging for Electric Vehicles; International Renewable Energy Agency (IRENA): Abu Dhabi, United Arab Emirates, 2019.

7. Chargepoint. Level Up Your EV Charging Knowledge. Available online: https://www.chargepoint.com/blog/level-your-evcharging-knowledge/ (accessed on 6 August 2020).

8. Godina, R.; Paterakis, N.G.; Erdinç, O.; Rodrigues, E.M.G.; Catalão, J.P.S. Impact of EV charging-at-work on an industrial client distribution transformer in a Portuguese Island. In Proceedings of the Australasian Universities Power Engineering Conference (AUPEC), Wollongong, Australia, 27-30 September 2015.

9. Godina, R.; Rodrigues, E.M.G.; Matias, J.C.O.; Catalão, J.P.S. Weekend charging impact of EVs on a residential distribution transformer in a Portuguese Island. In Proceedings of the 51st International Universities Power Engineering Conference (UPEC), Coimbra, Portugal, 6-9 September 2016.

10. Cross-Call, D. Matching Energy Storage to Small Island Electricity Systems: A Case Study of the Azores. Master's Thesis, Massachusetts Institute of Technology, Cambridge, MA, USA, September 2013.

11. Mahadeo, G.; Bahadoorsingh, S.; Sharma, C. Analysis of the impact of battery electric vehicles on the low voltage network of a Caribbean island. In Proceedings of the IEEE Transportation Electrification Conference and Expo (ITEC), Chicago, IL, USA, 22-24 June 2017.

12. Electric Power, Ministry of Energy and Energy Industries, Government of the Republic of Trinidad and Tobago. 2020. Available online: https:/ / www.energy.gov.tt/our-business/electric-power/ (accessed on 10 July 2020).

13. P.G.E. Voltage Tolerance Boundary. Available online: https://www.pge.com/includes/docs/pdfs/mybusiness/customerservice/ energystatus/powerquality/voltage_tolerance.pdf (accessed on 5 August 2020).

14. Park, Y.; Kim, D.; Huh, J.; Kim, Y. New and renewable energy policies of Jeju Island in Korea. In Proceedings of the World Renewable Energy Congress, Linköping, Sweden, 8-13 May 2011.

15. Kim, S.; Kim, H.; Lee, H.; Lee, J.; Lee, B.; Jang, G.; Lan, X.; Kim, T.; Jeon, D.; Kim, Y.; et al. Expanding power systems in the Republic of Korea: Feasibility studies and future challenges. IEEE Power Energy Mag. 2019, 17, 61-72. [CrossRef]

16. Chang, M.; Bae, S.; Yoon, G.; Park, S.; Choy, Y. Impact of electric vehicle charging demand on a Jeju Island radial distribution network. In Proceedings of the IEEE Power \& Energy Society Innovative Smart Grid Technologies Conference (ISGT), Washington, DC, USA, 17-20 February 2019.

17. Ehsani, M.; Falahi, M.; Lotfifard, S. Vehicle to grid services: Potential and applications. Energies 2012, 5, 4076-4090. [CrossRef]

18. National Renewable Energy Laboratory, Energy Snapshot Guadeloupe. Available online: https://www.nrel.gov/docs/fy15osti/ 64116.pdf (accessed on 5 August 2020).

19. Guérin, G.; Bucknall, P. High penetration of electric vehicles in an isolated grid: A study in Guadeloupe. In Proceedings of the IEEE 16th International Conference on Environment and Electrical Engineering (EEEIC), Florence, Italy, 7-10 June 2016.

20. Kadurek, P.; Ioakimidis, C.; Ferrao, P. Electric Vehicles and their impact to the electric grid in isolated systems. In Proceedings of the International Conference on Power Engineering, Energy and Electrical Drives, Lisbon, Portugal, 18-20 March 2009.

21. Jeong-yeo, J. Jeju strives to be global benchmark with carbon-free project. The Korea Herald, 8 May 2019.

22. Choi, W. Placement of Charging Infrastructures for EVs using K-Mean Algorithm and its validation using real usage data. Int. J. Precis. Eng. Manuf. Technol. 2020, 7, 875-884. [CrossRef]

23. Baatarbileg, A.; Otgongerel, Z.; Lee, G. Recent status of electric vehicle charging infrastructure in Jeju Island. In Proceedings of the IEEE Transportation Electrification Conference and Expo, Asia-Pacific (ITEC Asia-Pacific), Seogwipo-si, Korea, 8-10 May 2019.

24. Terna. Terna in Sardinia. Available online: https://download.terna.it/terna/0000/0859/94.PDF (accessed on 5 August 2020).

25. Porru, M.; Serpi, A.; Mureddu, M.; Damiano, A. A Combined planning and design approach of a public charging infrastructure for electric vehicles. In Proceedings of the IEEE Vehicle Power and Propulsion Conference (VPPC), Chicago, IL, USA, 27-30 August 2018.

26. Askja. Energy. Available online: https://askjaenergy.com/iceland-introduction/energy-data/ (accessed on 5 August 2020).

27. Wappelhorst, S. Iceland Is One the World's Most Interesting Electric Vehicle Markets. 9 July 2018. Available online: https: // theicct.org/blog/staff/iceland-ev-market-201807 (accessed on 25 October 2019).

28. Fontaine, A. 90 Electric Car Charging Stations in Reykjavík over Next Three Years. Available online: https:/ /grapevine.is/news / 2019/04/05/90-electric-car-charging-stations-in-reykjavik-over-next-three-years/ (accessed on 5 August 2020). 
29. Plan for World's First Electric Vehicle Only Island. 2018. Available online: https://www.electricvehiclesresearch.com/articles/16 005/plan-for-worlds-first-electric-vehicle-only-island (accessed on 10 July 2021).

30. VECTOR. Vector to Help Waiheke Island Become the World's First Fully Electrified Island. 2019. Available online: https: / / www.vector.co.nz/news/vector-to-help-waiheke (accessed on 25 October 2019).

31. Willuhn, M. Renault Deploys Smart EV Charging on Island Grid. Available online: https://www.pv-magazine.com/2018/09/24 / renault-deploys-smart-ev-charging-on-island-grid/ (accessed on 5 August 2020).

32. Edelstein, S. Renault Launches Second 'Smart Island' to Combine Electric Cars and Renewable Energy. 2018. Available online: https: / www.thedrive.com/tech/23747/renault-launches-second-smart-island-to-combine-electric-cars-and-renewableenergy (accessed on 5 October 2019).

33. Nizam, M.; Wicaksono, F.X.R. Design and optimization of solar, wind, and distributed energy resource (DER) hybrid power plant for electric vehicle (EV) charging station in rural area. In Proceedings of the 5th International Conference on Electric Vehicular Technology (ICEVT), Surakarta, Indonesia, 30-21 October 2018.

34. City Population. Labuan Bajo. Available online: https://www.citypopulation.de/php/indonesia-nusatenggaratimur.php? cityid $=5315010025$ (accessed on 10 July 2021).

35. Eras-Almeida, A.A.M.; Egido-Aguilera, A.; Blechinger, P.; Berendes, S.; Caamaño, E.; García-Alcalde, E. Decarbonizing the Galapagos Islands: Techno-economic perspectives for the hybrid renewable mini-grid Baltra-Santa Cruz. Sustainability 2020, 12, 2822. [CrossRef]

36. Clairand, J.M.; Arriaga, M.; Cañizares, C.A.; Álvarez-Bel, C. Power generation planning of Galapagos' microgrid considering electric vehicles and induction stoves. IEEE Trans. Sustain. Energy 2019, 10, 1916-1926. [CrossRef]

37. Ioakimidis, C.S.; Genikomsakis, K.N. Introduction of plug-in hybrid electric vehicles in an isolated island system. Adv. Build. Energy Res. 2017, 12, 66-83. [CrossRef]

38. Verzijlbergh, R.A.; Ilić, M.D.; Lukszo, Z. The role of electric vehicles on a green island. In Proceedings of the North American Power Symposium, Boston, MA, USA, 4-6 August 2011.

39. Rogers, T.; Gay, D.; Shirley, R. Zero-Carbon Electric Transport Already Reach Small Islands. 2019. Available online: https: / / www.greenbiz.com/article/zero-carbon-electric-transport-already-reach-small-islands (accessed on 1 July 2021).

40. The Electric Car and the Caribbean. Available online: https://www.caribbean-council.org/electric-car-caribbean/ (accessed on 30 October 2019).

41. Viscidi, L.; Graham, N.; Madrigal, M.; Masson, M.; Prado, V.; Monticelli, J. Electrified Islands: The Road to E-Mobility in the Caribbean. Report from the Inter-American Development Bank and the Organization of American States, and the Inter-American Dialogue. 2020. Available online: http://www.ecpamericas.org/assets/Site_18/files/Resources/2020/Electrified\%20Islands\% 20Final.pdf (accessed on 1 July 2021).

42. CARICOM; The Caribbean Centre for Renewable Energy and Energy Efficiency (CCREEE). CARICOM Regional Electric Vehicle Strategy (Revs) Framework. 2020. Available online: https://ccreee.org/document/regional-electric-vehicle-strategy-revsframework (accessed on 12 July 2021).

43. The Caribbean Centre for Renewable Energy and Energy Efficiency (CCREEE). The Future of E-Mobility in the Caribbean. 2020. Available online: https://ccreee.org/sites/default/files/documents / files/ccreee_brief_future_of_emobility_final.pdf (accessed on 11 July 2021).

44. Ellsmoor, J. The Electric Vehicle Revolution is Alive in Barbados. 2018. Available online: https://www.forbes.com/sites/ jamesellsmoor/2018/12/20/the-electric-vehicle-revolution-is-alive-in-barbados/\#25749ec05ff8 (accessed on 1 October 2019).

45. Forde-Craigg, S. Barbados Third Highest User of Electric Vehicles, Barbados Government Information Services. 2018. Available online: https: / /gisbarbados.gov.bb/blog/barbados-third-highest-user-of-electric-vehicles/ (accessed on 1 June 2021).

46. Nguyen, H.; Vo, V.; Le, T.; Phan, T.; Tran, T.; Nguyen, L. $\mathrm{CO}_{2}$ Reduction potential by putting electric vehicles into operation in Phu Quoc Island, Viet Nam. In Proceedings of the 2019 International Conference on System Science and Engineering (ICSSE), Dong Hoi, Vietnam, 19-21 July 2019.

47. Denny, E.; Keane, A. A smart integrated network for an offshore island. Proc. IEEE 2013, 101, 942-955. [CrossRef]

48. Camacho Alcocer, D.; Krams, B.; Körner, M.; Hantsch, F.; Martin, U.; Herzwurm, G. Electric vehicles in rural demand-responsive systems: Findings of two demand responsive transport projects for the improvement of service provision. World Electr. Veh. J. 2018, 9, 32. [CrossRef]

49. D'Elia, A.; Di Felice, M.; Bedogni, L.; Duckheim, M.; Mock, R.; Cinotti, T.S. From brown coal to a rural energy landscapeOrchestration of storage and electric mobility to foster decentralized energy management. In Proceedings of the IEEE 2nd International Forum on Research and Technologies for Society and Industry Leveraging a better tomorrow (RTSI), Bologna, Italy, 7-9 September 2016.

50. Selosse, S.; Ricci, O.; Garabedian, S.; Maïzi, N. Exploring sustainable energy future in Reunion Island. Util. Policy 2018, 55, 158-166. [CrossRef]

51. Thoma, K. Electric Vehicles in the Pacific Islands? An Investigation of the Possibilities of Electro-mobility in Samoa. Master's Thesis, Victoria University of Wellington, Wellington, New Zealand, 2014.

52. Petit, M.; Macire, M.; Codani, P.; Roy, F.; Maaroufi, M. Electrical energy and mobility issues in Africa: Which complementarities? In Proceedings of the IEEE PES Power Africa, Accra, Ghana, 27-30 June 2017. 
53. Šoltés, M.; Koberstaedt, S.; Lienkamp, I.M.; Rauchbart, S.; Frenkler, F. ACar-A electric vehicle concept for Sub-Saharan Africa. In Proceedings of the IEEE PES/IAS Power Africa, Cape Town, South Africa, 26-29 June 2018.

54. Jennings, R. How One Pollution-Weary Asian Island Adopted Electric Vehicles. 2019. Available online: https:/ /www.voanews. com/east-asia/how-one-pollution-weary-asian-island-adopted-electric-vehicles (accessed on 29 October 2019).

55. Sva'Bana, Y.M.K.; Sanjaya, K.H.; Svahilan, I. A preliminary design of electric scooter for sustainable tourist transportation. In Proceedings of the 2018 International Conference on Sustainable Energy Engineering and Application (ICSEEA), Tangerang, Indonesia, 1-2 November 2018.

56. Taibi, E.; Fernández, C. The impact of electric vehicles deployment on production cost in a Caribbean Island Country. In Proceedings of the Mobility Integration Symposium, Berlin, Germany, 23 October 2017.

57. Haakana, J.; Haapaniemi, J.; Lassila, J.; Partanen, J.; Niska, H.; Rautiainen, A. Effects of electric vehicles and heat pumps on long-term electricity consumption scenarios for rural areas in the nordic environment. In Proceedings of the 15th International Conference on the European Energy Market (EEM), Lodz, Poland, 27-29 June 2018.

58. Pfeifer, A.; Bošković, F.; Dobravec, V.; Matak, N.; Krajačić, G.; Duić, N.; Pukšec, T. Building smart energy systems on Croatian islands by increasing integration of renewable energy sources and electric vehicles. In Proceedings of the IEEE International Conference on Environment and Electrical Engineering and 2017 IEEE Industrial and Commercial Power Systems Europe (EEEIC/I\&CPS Europe), Milan, Italy, 6-9 June 2017.

59. Bremner, R. The fossil-free quest: How Renault is revolutionising a Portuguese island. AutoCar, 24 June 2019.

60. Tarek, R.; Anjum, A.; Hoque, M.A.; Azad, A. Solar electric ambulance van unfolding medical emergencies of rural Bangladesh. In Proceedings of the IEEE Global Humanitarian Technology Conference (GHTC), Seattle, WA, USA, 29 August 2016.

61. Pickup, O. Optimising transport, energy and infrastructure: Why we're all heading for this island's sustainable vision. The Telegraph, 6 December 2018.

62. Groupe Renault and EEM Create First Smart Island in Porto Santo. 2018. Available online: https://media.group.renault.com/ global/en-gb/groupe-renault/media/pressreleases/21204577 \protect \unhbox \voidb@x \hbox $\{/$ le-groupe-renault-et-eemcreent-la-premiere-ile-intelligente-a-p\} (accessed on 15 October 2019). 